\title{
GC-MS analysis of Adulterants in Captagon Tablet
}

\author{
Ali Zaid A Alshehri 1, *, Mohammed Saeed Al Qahtani1,*, Mohammed Aedh Al \\ qahtani1, ${ }^{*}$, Abdulhadi M Faeq1, 1*, Jawad Aljohani 1,*
}

\section{Ammar Al-Farga ${ }^{2, *}$}

${ }^{1}$ Department of Medical Laboratory Technology, College of Applied Medical Sciences, University of Jeddah. ${ }^{2}$ Department of Biochemistry, Faculty of Science, University of Jeddah, Saudi Arabia

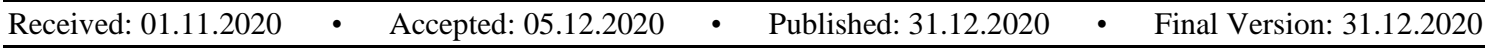

\begin{abstract}
Background: In secret laboratories various synthetic or semi-synthetic amphetamine-type stimulants (ATS) are produced and processed. Stimulants of the form of amphetamine (ATS) are the second most common illegal drugs used worldwide, following cannabis. ATS production has increased worldwide, particularly from the Middle East. Fenethylline (CaptagonTM), a derivative of amphetamine, is commonly marketed as a street drug. Objective: this research aimed at applying gas chromatography / mass spectrometry (GC / MS) for fenethylline profiling of confiscated samples from the Saudi market. Methodology: The study of GC / MS was conducted on a general-purpose column (30 mm $0.25 \mathrm{~mm}$ i.d) filled with $0.25 \mathrm{~mm}$ cross bond, $5 \%$ diphenyl dimethyl polysiloxane (Rtx-5MS). The mass was worked in the process of impacting the electron. Results and discussion: Analyzed samples showed positive results for amphetamine in concentrations ranging from 0.07 to 43.02 percent of the substance in 60 percent of the samples. Caffeine was also present in 60 per cent of the samples at levels between 0.61 and 60.31 per cent. In the MS of the other active compounds were recorded in different proportions. Lastly, the presence of other substances in fenethylline samples may contribute to intoxication.
\end{abstract}

Keywords: Adulteration, captagon, fenethylline, Chromatographic, illicit.

\section{Introduction}

ATS are synthetic compounds belonging to the central nervous system (CNS) stimulant class to produce adrenaline-like effects such as amphetamine, methamphetamine, fenethylline, methylphenidate and dextroamphetamine [1,2]. ATS are the second most commonly used illicit drugs worldwide after cannabis. The number of users of ATS according to the United Nations Office on Drugs and Crime [3,4]. Fenethylline, 7-(2-amethyl-aminoethyl)-theophylline, is an amphetaminederivative of theophylline. It is a psychoactive drug that is similar in many respects to amphetamine [5]. During the 1960s and 1970s fenethylline was used for its effects on antinarcotics and antidepressants. It has also been shown to be effective in treating childhood selective attention disorder. Fenethylline does not cause a noticeable rise in the blood pressure of the subjects being

\footnotetext{
* Corresponding Author: Ammar Al-Farga

Tel: +96 553438120

E-mail address: alfargah83@gmail.com
} 
treated as opposed to amphetamines [6]. Fenethylline is not actually used in any FDA-approved medicines. Unlike prescription drugs like heroin and cocaine, ATS with specific household chemicals and solvents that are readily available from commercial sources is fairly easy to produce. Furthermore, methods of manufacturing these products are readily available on the Internet [7]. This leads to the widespread (illegal) distribution of such designer drugs by many highly adulterated populations. ATS is never sold or used in its purest form, as opposed to many other illicit drugs. These are also heavily mixed with a range of additives, adulterants and/or diluents in order to increase the apparent amount of the drug, thereby maximizing the dealer's profit. It is very important to recognize potentially harmful substances that contaminate illicit drugs, because they could be more dangerous than the drug itself [8]. Fenethylline was used during the 1960s and 1970s for its antinarcotic and antidepressant effects. This has also been shown to be effective in treating childhood deficit attention disorder [6]. Captagon, the brand name of the stimulant Fenethylline [12,13], was first mentioned by a German pharmacist in 1961 for potential treatment of hyperactivity, depression and narcolepsy [12]. However, the United States (1981) and the World Health Organization (1986) classified it as a regulated drug because of its addictive and hallucinogenic effects, making it appropriate for prescription or sale. Captagon is metabolized into Amphetamine (24.5\% oral) and Theophylline (13.7\% oral), as shown in Fig. 1. Thus, the pharmacological activity of captagon is believed to be the result of the combined action of those two metabolites. Amphetamine, the main metabolite of Captagon, is a CNS stimulator capable of enhancing alertness, increasing concentration/ physical performance and creating a sense of well-being, motivation and aggression. This can be used in the treatment of hyperactive disorder (ADHD) with obesity, narcolepsy and attention deficit [14]. Amphetamine can be an agonist of central 5-HT receptors [15-16]. The object of the study was to apply gas chromatography / mass spectrometry (GC / MS) for captagon profiling of seized samples from the Saudi market collected. It is necessary to classify these potentially dangerous substances that contaminate Captagon as these substances may be more harmful than the Captagon itself.

\section{Materials and methods}

\subsection{Materials and reagents}

In this study, 60 samples were collected from several agencies such as poison control centers and forensic medical chemistry in the Kingdom of Saudi Arabia and from the General Directorate for Narcotics Control in Riyadh, Ministry of Interior. Methanol (HPLC grade 99.8 \%) was provided by Fisher scientific Co (Leicestershire, UK). Calbrated Centrifuge Thermo Scientific Lab of UGE 400.ULtrasonic Cleaner SQ 150 B "ECHO GOLD KANG TRADING L.L.C "Vortex Mixer (VELP. SCIENTIFICA). Vials and accessories ( Thermo scientific ), Graduated Volumetric Cylinder "Flask beaker" Calbrated Pipette "variable volume piston type" Eppendorf Research plus: $(10100 \mu \mathrm{L} / 20$ $200 \mu 1001000 \mu \mathrm{L} / 0.55 \mathrm{ML}$ )Polyspring insert, $150 \mathrm{UL}, 100 \mathrm{PK}$ “ THERMO SCIENTIFIC "Hypodermic syringe 5 ML, 3 ML " RAMY COMPONY "2.0 ML Clear Vial ( C 40131 ) Kit PTFE / SILICONE SEPTUM THERMO SCIENTIFIC "Disposable culture tubes "16 100 mm FISHER BRAND. Tips and Parafilm "BEMIS COMPONY". The GC/ MS analysis was performed on Shimatdzu QP 2010 ultra (JAPAN). All standard (Amphetamine Caffeine Tramadol Methamphetamine) were purchased from Cerilliant Company. The other substances (Lidocaine Diphenhydramine Dextromethorphan Acetaminophen) were purchased as certified by Saudi SFDA pharmaceutical products:

-XYLOCAINE PUMP SPRAY $10 \%(10 \mathrm{mg} / \mathrm{dose})$ in order Lidocaine -PANADOL NIGHT $25 \mathrm{mg}$ in order Diphenhydramine 
-CONTRA TM $15 \mathrm{mg}$ in order Dextromethorphan

-SOLPADEINE $500 \mathrm{mg}$ in order Acetaminophen.

\subsection{Sample preparation}

The data for each of the 60 samples was recorded in terms of (weight type color containing the captagon sign) and finely powdered by a mortar. The sample was taken (one tablet) and dissolved in $2 \mathrm{ml}$ of methanol and vortexed for 2 minutes. Then it was placed with a device (ultrasonic) to ensure that all the compounds of the dissolved substance were dissolved for 45 minutes. The solution was completed to the volume with methanol, then centrifuged at $4000 \mathrm{rpm}$ for $2 \mathrm{~min}$, then we separate the clearance from the solution into disposable culture tubes $16100 \mathrm{~mm}$. The sample was separated and taken $100 \mu \mathrm{l}$ of the clearance solution into vial $(2 \mathrm{ml})$, then adding $1.9 \mathrm{ml}$ of methanol , and injecting it into the injection tube on the GC MS .

\section{Results and discussion}

Captagon tablets are prepared as a unit dosage like pharmaceutical tablets. Comprehensive physical and chemical analysis of Captagon tablets produced results that could be helpful to determine its comparative features to find the source. Amphetamine tablets sent seized by different places were 8 different types found among the 60 tablets sampled. Tablets are prepared as a unit dosage like pharmaceutical tablets. The chemical structures of the Acetaminophen, Lidocaine, Diphenhydramine, Formetorex, Trihexyphenidyl, Theophylline, Caffeine, Amphetamine, Propylparaben, Dextroamphetamineand Propyphenazone are shown in Fig. 2.

\subsection{Mass spectrometry}

The results obtained showed of analyzed amphetamines tablets the differences in Captagon levels with the adulterants and diluents, with the average prevalence of amphetamine to $100 \%$ in 60 tablets of 60 tablets, while the Biperiden was the lowest percentage of additives with $5 \%$ in 60 tablets. All these components and their ratios in Captagon tablets are analyzed and demonstrated in Table 1. These components and their ratios in Captagon tablets that analyzed demonstrated in Table 1. The average concentration was calculated in all tablets samples, where found that Amphetamine 100\%, caffeine 100\%, Lidocaine 46\%, Diphenhydamine 100\%, Biperiden 3.3\% and Ephedrine 1.66\% (Table 2). Average concentration of component found in Captagon tablets sample analyzed is demonstrated in Table 2. Moreover, the results of concentration of adulterants and diluents Gives us a broad perception of the sources of these tablets and their toxicity and the seriousness of their components on the health of users as demonstrated in table. 2. Mass spectrometry is the standard method for identity confirmation of suspected drugs in forensic samples. The obtained MS spectra revealed the presence of several compounds adulterating in seized CaptagonTM tablets. Figure 4show representative EI mass spectra of 12 of the most common adulterants found in seized tablets. Since the compounds examined belong to different chemical identities, the distinguishing between them using their MS spectra was simple. The MS of these compounds provide structural details for differentiating between this group of compounds, as all major fragment ions occur at different masses. A list of the most common adulterants 14 compounds with their retention times and major fragment ions were given in Table 3. The applied GC-MS method was based on the reference [910]. The results were compared with full mass spectra and selected ion monitoring (SIM) for all substances with reference to Wiley library which contains spectra for 638,000 general compounds. Normalization method was also used to determine the amount of additive substances by using $\%$ area under the peak (AUP). The more volatile impurities which elute before $2 \mathrm{~min}$ are less useful for 
characterization and more readily disappear on prolonged storage. Nearly no significant impurities eluted after $27 \mathrm{~min}$, and a plasticizer peak with little evidence value may also be present in this area. Analytical data obtained from GC/MS chromatograms and mass spectra demonstrated that all 60 CaptagonTM tablets contained one or more adulterants. In this regard, it is interesting to note that the absence of fenethylline, the active ingredient in CaptagonTM tablets, with the presence of amphetamine and caffeine in all tablets can be related to the inappropriate manufacturing method of the seized tablets resulting in the predominance of these starting materials without the final desired compound, fenethylline[28]. Table 4 indicates the relative frequency of the 8 adulterants contained in the tablets with their concentration ranges $\left(\mathrm{n}^{1} / 460\right)$. According to the data in Table 2, positive tests for amphetamine were observed in 60 per cent of the samples (n1/460) in concentrations ranging from 0.07 to 43.02 per cent of the material. Caffeine was also present at levels between 0.61 and 60.31 per cent in 60 per cent of the samples. Other active compounds have been reported in various proportions in the MS of the analyzed samples, as shown in Table 4. These compounds were Acetaminophen, Diphenhydramine, Dextromethorphan, Methamphetamine, Lidocaine, and Tramadol.

\section{Conclusion}

A simple and rapid method for direct separation and determination of a range of CaptagonTM in GC - MS seized tablets is described in this report. Such scanning system mode is an excellent test system for CaptagonTM. It provides sensitivity and selectivity which makes the present study a method of choice. The analytical method has been used successfully on authentic samples obtained from seniors. GC-MS is a really effective way to test a drug in scanning mode. It gives both sensitivity and selectivity which makes this study a choice process. The presence of impurities in the fenethylline / amphetamine profile indicates the drug is illegal. Nearly all the fenethylline/ amphetamine sold is synthesized illegally. The isolation of the psychoactive drug fenethylline/ amphetamine from co-extinguishing adulterating compounds was evaluated using the isolation ability of GC along with the identification of the structure of mass spectrometry (GCMS).The standard EI mass spectra provide useful structural information for separating these compounds from one another. Adulteration on seized CaptagonTM tablets obtained from the Saudi market (n1/460) has been successfully identified using this method. All confiscated tablets showed promising results in the synthesis of the desired drug, fenethylline, as the starting material for amphetamine.It adds to the high propensity of CaptagonTM abuse in Saudi Arabia, offering the potential risk of amphetamine over fenethylline. Nearly 14 adulterants were commonly found in confiscated samples that could raise the incidence of lethality due to their toxic impact, a major health problem that should be given more attention in recent years.

\section{Reference}

[1] Shadloo, B., Amin-Esmaeili, M., Haft-Baradaran, M., Noroozi, A., Ghorban-Jahromi, R., \& RahimiMovaghar, A. (2017). Use of amphetamine-type stimulants in the Islamic Republic of Iran, 2004-2015: a review. Eastern Mediterranean Health Journal, 23(3).

[2] WHO WPRO. (2017). Patterns and consequences of the use of amphetamine-type stimulants (ATS). World Health Organization. http://www.wpro.who.int/hiv/documents/docs/.

[3] UNODC. (2016). World Drug Report. [online] Vienna: United Nations Office on Drugs and Crime. https://www.unodc.org/.

[4] UNODC. (2017). World Drug Report. [online] Vienna: United Nations Office on Drugs and Crime. https://www.unodc.org/. 
[5] Sweetman, S. C.. (2002). Martindale. The complete drug reference, 36, 3694.

[6] Kikura, R., \& Nakahara, Y. (1997). Hair analysis for drugs of abuse XVI. Disposition of fenethylline and its metabolite into hair and discrimination between fenethylline use and amphetamine use by hair analysis. Journal of analytical toxicology, 21(4), 291-296.

[7] Spektrometri, P. A. K. G., DESA, W., \& ISMAIL, D. (2017). Impurity Profiling of Amphetamine and Methamphetamine Using Gas Chromatography Mass Spectrometry (GCMS) Harmonised Methods. Sains Malaysiana, 46(1), 149-156.

[8] Andreasen, M. F., Lindholst, C., \& Kaa, E. (2009). Adulterants and diluents in heroin, amphetamine, and cocaine found on the illicit drug market in Aarhus, Denmark. The Open Forensic Science Journal, 2(1).

[9] Man, C. N.; Nor, N. M.; Lajis, R.; Harn, G. L.(2009). Identification of Sildenafil, Tadalafil and Vardenafil by Gas Chromatography- Mass Spectrometry on Short Capillary Column. J Chromatogr A, 1216, 84268430 .

[10] Aljohar, H. I., Abuhaimed, S. N., Maher, H. M., Nafisah, B. A., \& Alkhalaf, A. M. (2019). Gas chromatography tandem mass spectrometry for the screening of adulterants in seized captagon ${ }^{\mathrm{TM}}$ tablets. Journal of Liquid Chromatography \& Related Technologies, 42(11-12), 358-366.

[11] Kristen, G., Schaefer, A. \& Von Schlichtegroll, A.(1986). Fenetylline: therapeutic use, misuse and/or abuse. Drug and alcohol dependence 17, 259-271.

[12] Katselou, M., Papoutsis, I., Nikolaou, P., Qammaz, S., Spiliopoulou, C., \& Athanaselis, S. (2016). Fenethylline (captagon) abuse-local problems from an old drug become universal. Basic \& clinical pharmacology \& toxicology, 119(2), 133-140.

[13] Heal, D. J., Smith, S. L., Gosden, J. \& Nutt, D. J.(2013). Amphetamine, past and present-a pharmacological and clinical perspective. Journalof Psychopharmacology 27, 479-496.

[14]Dowd, C. S., Herrick-Davis, K., Egan, C., DuPre, A., Smith, C., Teitler, M., \& Glennon, R. A. (2000). 1-[4(3-Phenylalkyl) phenyl]-2-aminopropanes as 5-HT2A partial agonists. Journal of medicinal chemistry, 43(16), 3074-3084.

[15] Glennon, R. A., Raghupathi, R., Bartyzel, P., Teitler, M. \& Leonhardt, S.(1992). Binding of phenylalkylamine derivatives at 5-HT1C and5-HT2 serotonin receptors: evidence for a lack of selectivity. Journal of medicinal chemistry $35,734-740$.

[16] Vilches-Herrera, M., Miranda-Sepúlveda, J., Rebolledo-Fuentes, M., Fierro, A., Lühr, S., Iturriaga-Vasquez, P., ... \& Reyes-Parada, M. (2009). Naphthylisopropylamine and N-benzylamphetamine derivatives as monoamine oxidase inhibitors. Bioorganic \& medicinal chemistry, 17(6), 2452-2460. 
Table 1. The components found

and their proportions in Captagon tablets samples that analyzed

\begin{tabular}{|ccc|}
\hline 2.1. Component & $\begin{array}{c}\text { 2.2. Times found } \\
\text { positive }\end{array}$ & 2.3. Percentage \\
\hline Amphetamine & 60 & $100 \%$ \\
Methamphetamine & 41 & $68.3 \%$ \\
Acetaminophen & 44 & $73.3 \%$ \\
Caffeine & 60 & $100 \%$ \\
Diphenhydramine & 60 & $100 \%$ \\
Lidocaine & 60 & $100 \%$ \\
Tramadol & 25 & $41.6 \%$ \\
Dextromethorphan & 53 & $88.3 \%$ \\
Theophylline & 15 & $25 \%$ \\
Chlorpheniramine & 4 & $6.66 \%$ \\
Biperiden & 2 & $3.33 \%$ \\
Ephedrine & 1 & $1.66 \%$ \\
Quinine & 8 & $13.33 \%$ \\
Procaine & 3 & $5 \%$ \\
Chlorpheniramine & 4 & $6.66 \%$ \\
Biperiden & 2 & $3.33 \%$ \\
\hline
\end{tabular}

Table 2. Average concentration of components found in Captagon tablets samples that analyzed

\begin{tabular}{|cc|}
\hline Component & Average \\
\hline Amphetamine & $100 \%$ \\
Caffeine & $100 \%$ \\
Lidocaine & $100 \%$ \\
Diphenhydami & $100 \%$ \\
Dextromethorphan & $88.3 \%$ \\
Acetaminophen & $73.3 \%$ \\
Methamphetamine & $68.3 \%$ \\
Tramadol & $41.6 \%$ \\
Theophylline & $25 \%$ \\
Quinine & $13.33 \%$ \\
Acetamide & $10 \%$ \\
Chlorpheniramine & $6.66 \%$ \\
Procaine & $5 \%$ \\
Biperiden & $3.33 \%$ \\
Ephedrine & $1.66 \%$
\end{tabular}


Table 3. A list of the most common possible adulterants found in seized CaptagonTM tablets.

\begin{tabular}{|c|c|c|}
\hline Compound & $\begin{array}{c}\text { Retention Time } \\
(\mathbf{m i n}), \mathbf{t R}\end{array}$ & Major fragment ions m/z \\
\hline Amphetamine & 7.83 & $44,91,65,51,120,63,92,77$ \\
\hline Methamphetamine & 9.19 & $58,91,56,65,59,134,77$ \\
\hline Acetaminophen & 15.656 & $109,151,43,80,108,110,152,81$ \\
\hline Caffeine & 17.21 & $194,109,55,67,193,195,110,81,82$ \\
\hline Diphenhydramine & 17.39 & $58,73,77,165,42,167,152,166$ \\
\hline Lidocaine & 17.48 & $56,58,87,30,72,120,56,77,91,42$ \\
\hline Tramadol & 18.27 & $58,263,46,59,44,30,135,264$ \\
\hline Dextromethorphan & 20.1 & $271,59,150,270,214,272,171,212,213,31$ \\
\hline Theophylline & 13.63 & $180,95,68,53,41,123,67,96,40$ \\
\hline Formetorex & 7.6 & $118,72,44,91,117,65,119,92,51$ \\
\hline Chlorpheniramine & 16.9 & $203,58,205,167,202,204,72,168,166$ \\
\hline Biperiden & 17.2 & $98,218,55,99,42,77,44,84$ \\
\hline Ephedrine & 13.8 & $58,77,56,42,79,105,59$ \\
\hline Quinine & 20.08 & $136,41,42,81,137,55,117,36,79,53$ \\
\hline
\end{tabular}

Table 4 The relative occurrence of the most common 8 adulterants in the investigated samples $\left(\mathbf{n}^{1 / 460}\right)$.

\begin{tabular}{|c|c|c|}
\hline 2.4. Compounds & 2.5. \% Relative occurrence & 2.6. Range \\
\hline Amphetamine & 60 & $0.07-43.02$ \\
\hline Caffeine & 60 & $0.61-60.31$ \\
\hline Acetaminophen & 44 & $0.30-31.32$ \\
\hline Diphenhydramine & 60 & $0.16-6.30$ \\
\hline Dextromethorphan & 53 & $0.04-8.11$ \\
\hline Methamphetamine & 41 & $0.03-18.83$ \\
\hline Lidocaine & 60 & $0.22-2.62$ \\
\hline Tramadol & 25 & $0.04-8.3$ \\
\hline
\end{tabular}<smiles>CC(Cc1ccccc1)NCCn1cnc2c1c(=O)n(C)c(=O)n2C</smiles>

\section{Captagon}

(Fenethylline)

Amphetamine

Main cause of addiction
Markedly attenuates behavioral sensitization to repeated amphetamine exposure 


\section{Fig.1. Metabolic scheme of Captagon (Fenethylline)}

When Captagon orally dosed, it will go through the oxidative metabolism via cytochrome P450 (CYP450) enzyme, and in final be metabolized into 24.5\% Amphetamine and 13.7\% Theophylline. Amphetamine is the main cause of addiction, while Theophylline reduces the behavioral sensitization to repeated Amphetamine exposure, thus explains the less addictiveness of Fenethylline than Amphetamine.

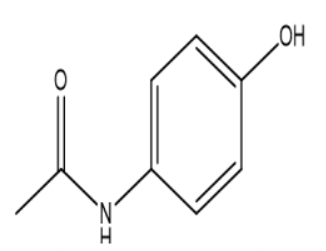

Acetaminophen

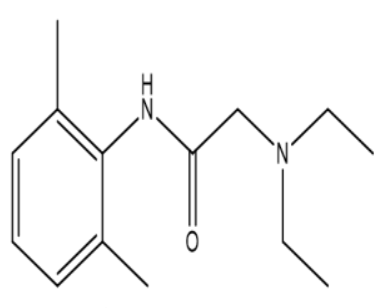

Lidocaine

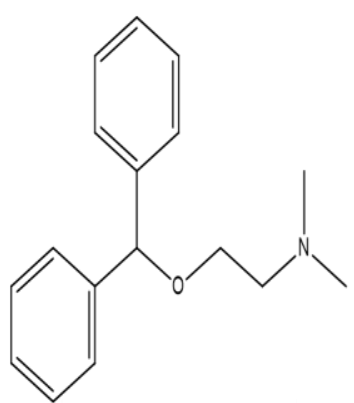

Diphenhydramine

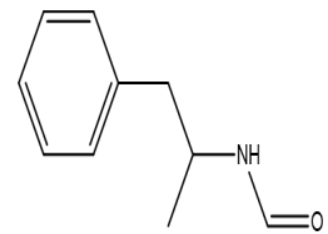

Formetorex<smiles>OC(CCN1CCCCC1)(c1ccccc1)C1CCCCC1</smiles>

Trihexyphenidyl<smiles>Cn1c(=O)c2[nH]cnc2n(C)c1=O</smiles>

Theophylline<smiles>Cn1c(=O)c2c(ncn2C)n(C)c1=O</smiles>

Caffeine

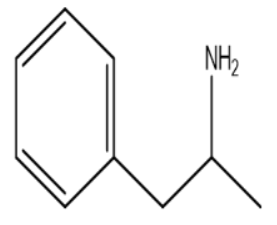

Amphetamine<smiles>CCCOC(=O)c1ccc(O)cc1</smiles>

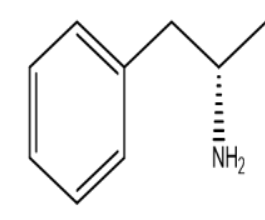

Dextroamphetamine

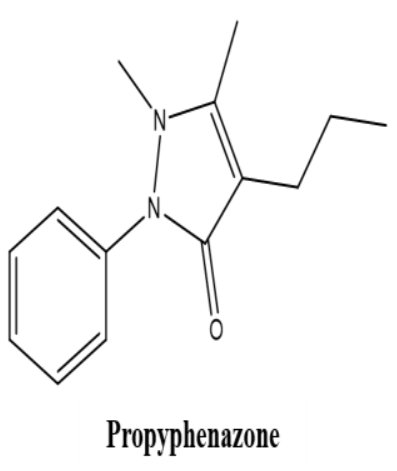

Fig. 2. The chemical structures of captagon, adulterants and diluents. 